\title{
ОЦЕНКА УРОВНЯ ИСПОЛЬЗОВАНИЯ И ПРОБЛЕМЫ ОПРЕДЕЛЕНИЯ ПОТЕНЦИАЛЬНЫХ ВОЗМОЖНОСТЕЙ ПРЕДПРИЯТИЙ
}

\begin{abstract}
АНнОТАЦИЯ. Производственные мощности отражают возможности факторов производства или предприятия в целом по выпуску продукции. Определение мощностей необходимо для обоснования планов производства продукции, оценки уровня конкурентоспособности продукции, разработки балансов производственных мощностей и мероприятий по сокращению диспропорций и «узких» мест в производстве. В работе проанализирован уровень использования производственных мощностей по основным видам промышленной продукции за 1992-2015 гг. Коэффициент использования производственных мощностей в промышленности России в настоящее время составляет около 60-65 \%. Производственный потенциал предприятия определяется как совокупность его производственных ресурсов. В статье рассмотрены характерные особенности производственного потенциала предприятия, выделена их сущность и сферы применения. Предложена классификация характерных особенностей потенциала, предусматривающая их разделение на структурные и результирующие особенности. Рассмотрены методы расчета величины производственного потенциала и сделан вывод, что наибольшее практическое значение имеет стоимостный метод, который может быть использован для определения стоимости предприятия. Оценка предприятий может проводиться различными методами, базирующимися на затратном, сравнительном и доходном подходах. При использовании каждого из них предлагается учитывать информацию о величине производственного потенциала предприятия и ресурсов, входящих в его состав.
\end{abstract}

КЛЮЧЕВЫЕ СЛОВА. Производственная мощность; использование мощностей; производственный потенциал; характерные особенности потенциала; методы определения потенциала; определение стоимости предприятия.

ИНФОРМАЦИЯ О СТАТЬЕ. Дата поступления 7 апреля 2017 г.; дата принятия к печати 2 мая 2017 г.; дата онлайн-размещения 22 июня 2017 г.

M. I. Tertyshnik

Baikal State University, Irkutsk, Russian Federation

\section{ASSESSING LEVEL OF USE AND PROBLEMS OF DETERMINING PERFORMANCE POTENTIAL OF BUSINESSES}

\begin{abstract}
Production facilities reflect the capabilities of production factors or of a business as a whole in product manufacture. Determining the facilities is necessary to justify the production plans, to assess the level of product competitiveness, to develop production facility balances and measures to reduce imbalances and «bottlenecks» in production. The article analyses the level of utilizing production facilities in terms of main types of industrial products over the period of 1992-2015. The ratio of production facility use in Russia's industry is currently about 60-65\%. The business's production potential of an enterprise is determined as an aggregate of its production resources. The article examines the characteristic features of the business's production potential, identifies their essence and spheres of use. It offers a classification of the characteristic features of the potential which envisages their separation into structural and resulting features. It considers the methods of calculating the value of the industrial potential and draws a conclusion that of the most practical significance is the cost method which can be used for assessing the cost of the business. Assessing
\end{abstract}

(C) М. И. Тертышник, 2017

\section{Baikal Research Journal}


businesses can be carried out by various methods based on the cost, comparative and revenue approaches. In using each of them, it is proposed to consider the information of the value of the business's production potential and the resources it incorporates. KEYWORDS. Production capacity; utilization of capacities; production potential; characteristic features of potential; methods of determining potential;, determining business's cost.

ARTICLE INFO. Received April 7, 2017; accepted May 2, 2017; available online June 22, 2017.

Различные аспекты определения потенциальных возможностей исследованы в работах многих авторов [1-5]. Для характеристики этого понятия используются такие экономические категории как производственная мощность и производственный потенциал предприятия.

Оценка производственных мощностей в деятельности предприятий занимает важное место. От точности и достоверности трактовки этого понятия, выбора метода расчета, определения факторов, влияющих на ее величину и степень использования, расчета величины резервов мощностей зависит степень обоснованности плана производства продукции и, в конечной степени, результаты работы предприятия.

Традиционно, производственная мощность рассматривается как возможность средств труда к производству продукции за год, квартал, месяц, сутки, смену. Начиная с 90-х гг. прошлого века годы стал применяться более широкий подход $\kappa$ определению производственных мощностей, как способностей предприятия к производству продукции за тот или иной период времени. Этот подход к определению мощностей является более обоснованным, так как возможности предприятия по выпуску продукции определяются не только производительностью оборудования, но и требуют также наличия сырья определенного качества, квалифицированного персонала и других факторов производства.

Уровень использования мощностей характеризует коэффициент использования мощностей, который может определяться в относительных величинах и в процентах. В 70-80 гг. XX в. органы статистики нашей страны проводили исследования уровня использования производственной мощности по выпуску 130-240 основных видов промышленной продукции. В течение этого периода времени значение данного показателя в промышленности России находилось в среднем на уровне 85-90\%. В последние годы Федеральная служба государственной статистики анализирует уровень использования производственной мощности по выпуску 80 видов промышленной продукции, его среднее значение составляет около 60-65\%. Такое значительное снижение этого показателя объясняется, прежде всего, общим падением объема производства продукции и высоким уровнем износа основных фондов. Уровень загрузки мощностей существенно отличается по отдельным отраслям и производствам промышленности. Высокий уровень использования производственных мощностей наблюдается в черной металлургии (в производстве чугуна $-94 \%$, стали $-82 \%$, проката $80 \%$ ), по отдельным видам химической продукции (аммиак $-94 \%$, серная кислота $-73 \%)$, в производствах плит древесно-стружечных $-82 \%$, бумаги $-87 \%$, угля $-82 \%$, сахара-песка $-89 \%$. Низкий уровень использования производственных мощностей существует в машиностроительной промышленности (в производстве кранов мостовых - $20 \%$, металлорежущих станков $17 \%$, турбин паровых - $20 \%$, тракторов - $10 \%)$, в производстве тканей 24-27\%, масла животного - 36 \% и др.

В экономической литературе выделяются различные точки зрения по проблеме, связанной с определением понятия «производственный потенциал» [6-11]. Широкое применение получил ресурсный подход, исходя из которого производ-

\section{Baikal Research Journal}

электронный научный журнал Байкальского государственного университета 
ственный потенциал включает в себя совокупность производственных ресурсов предприятия. Можно выделить два направления изучения этой категории:

- производственный потенциал характеризуется только определенными производственными ресурсами;

- под производственным потенциалом предприятия понимается совокупность производственных ресурсов, связанных с производством определенной продукции.

Таким образом, производственный потенциал является системой, состоящей из определенного набора производственных ресурсов или факторов производства. Системный подход к определению производственного потенциала позволяет выделить следующие его характерные особенности, которые представлены в табл. 1.

Сущность и сферы приленения характерных особенностей производственного потенциала предприятия

\begin{tabular}{|c|c|c|}
\hline Особенность & Сущность особенности & Сферы применения \\
\hline Целостность & $\begin{array}{l}\text { Означает, что создание и использование производственного } \\
\text { потенциала должно быть направлено на решение главной } \\
\text { задачи предприятия - получение максимальной прибыли } \\
\text { за счет повышения эффективности производства. Поэтому } \\
\text { эффективно должен использоваться не только весь произ- } \\
\text { водственный потенциал предприятия, но и входящие в его } \\
\text { состав основные элементы }\end{array}$ & $\begin{array}{l}\text { Определение } \\
\text { состава производ- } \\
\text { ственного потен- } \\
\text { циала предприя- } \\
\text { тия }\end{array}$ \\
\hline Сложность & $\begin{array}{l}\text { Основывается на том, что в любой системе каждый из эле- } \\
\text { ментов рассматривается как состоящий из отдельных подэле- } \\
\text { ментов, в результате чего система имеет сложную структуру. } \\
\text { Производственный потенциал состоит из четырех основных } \\
\text { производственных ресурсов (элементов), которые в дальней- } \\
\text { шем подразделяются на составляющие их подэлементы. На- } \\
\text { пример, персонал предприятия делится на основной (произ- } \\
\text { водственный) и неосновной (непроизводственный). Основной } \\
\text { персонал подразделяется на рабочих и служащих. В свою } \\
\text { очередь в составе рабочих выделяются основные и вспомо- } \\
\text { гательные рабочие, в составе служащих - руководители, } \\
\text { специалисты и другие служащие. Подобным образом может } \\
\text { рассматриваться состав и других элементов потенциала }\end{array}$ & $\begin{array}{l}\text { Характеризует } \\
\text { структуру про- } \\
\text { изводственного } \\
\text { потенциала пред- } \\
\text { приятия }\end{array}$ \\
\hline $\begin{array}{l}\text { Взаимоза- } \\
\text { меняемость } \\
\text { или альтер- } \\
\text { нативность } \\
\text { элементов } \\
\text { производ- } \\
\text { ственного } \\
\text { потенциала }\end{array}$ & $\begin{array}{l}\text { Характеризуется тем, что каждый из производственных } \\
\text { ресурсов может заменять другой ресурс, в результате этого } \\
\text { возможно или изменение стоимости отдельных ресур- } \\
\text { сов, или изменение удельных весов ресурсов в структуре } \\
\text { производственного потенциала предприятия. Например, } \\
\text { увеличение стоимости основных фондов в результате рекон- } \\
\text { струкции производства может быть связано со снижением } \\
\text { доли и стоимости персонала в структуре производственно- } \\
\text { го потенциала предприятия. Можно выделить следующие } \\
\text { свойства взаимозаменяемости: } \\
\text { 1. Регламентированность. Предполагает, что производствен- } \\
\text { ные ресурсы могут постоянно заменять друг друга. Но для } \\
\text { выпуска продукции необходимо наличие каждого из ре- } \\
\text { сурсов. Поэтому выделяются границы взаимозаменяемости } \\
\text { элементов потенциала, которые определяются применяемой } \\
\text { технологией производства. Нижняя граница соответствует } \\
\text { наиболее простым технологиям производства, а верхняя } \\
\text { граница взаимозаменяемости достигается при такой структу- } \\
\text { ре произодственного потенциала, который характерен для } \\
\text { передовых технологий производства. При этом, чем сложнее } \\
\text { технология производства, тем больше в структуре потенци- } \\
\text { ала удельный вес основных фондов, технологий и информа- } \\
\text { ции и ниже доля персонала. И, наоборот, чем проще тех- } \\
\text { нологический процесс, тем больше доля персонала и ниже } \\
\text { удельный вес основных фондов, технологий и информации. }\end{array}$ & $\begin{array}{l}\text { Отражает возмож- } \\
\text { ность изменения } \\
\text { состава элементов } \\
\text { производственного } \\
\text { потенциала пред- } \\
\text { приятия }\end{array}$ \\
\hline
\end{tabular}

\section{Baikal Research Journal}

электронный научный журнал Байкальского государственного университета 
Окончание табл. 1

\begin{tabular}{|c|c|c|}
\hline Особенность & Сущность особенности & Сферы применения \\
\hline & $\begin{array}{l}\text { 2. Периодичность. Характеризуется тем, что взаимозаме- } \\
\text { няемость ресурсов не происходит постоянно. Это связано с } \\
\text { тем, что изменения внутри производственного потенциала } \\
\text { требуют крупных инвестиций. Кроме того, все производ- } \\
\text { ственные ресурсы подвергаются моральному старению (мо- } \\
\text { ральный износ основных фондов, устаревание технологий, } \\
\text { информации, знаний персонала). Срок морального износа } \\
\text { определяет периодичность взаимозаменяемости ресурсов } \\
\text { 3. Способность достигать сбалансированного равновесия } \\
\text { элементов производственного потенциала. При определен- } \\
\text { ном уровне развития производства изменение структуры } \\
\text { производственного потенциала становится неэффективными } \\
\text { и сбалансированность его ресурсов }\end{array}$ & \\
\hline $\begin{array}{l}\text { Взаимос- } \\
\text { вязь и взаи- } \\
\text { модействие } \\
\text { элементов } \\
\text { производ- } \\
\text { ственного } \\
\text { потенциала } \\
\end{array}$ & $\begin{array}{l}\text { Связана с тем, что все производственные ресурсы связаны } \\
\text { между собой и при изменении какого-либо из них проис- } \\
\text { ходят изменения в других ресурсах, входящих в состав } \\
\text { потенциала }\end{array}$ & $\begin{array}{l}\text { Характеризует } \\
\text { структуру про- } \\
\text { изводственно- } \\
\text { го потенциала } \\
\text { предприятия и } \\
\text { возможность ее } \\
\text { изменения }\end{array}$ \\
\hline $\begin{array}{l}\text { Способность } \\
\text { к восприя- } \\
\text { тию дости- } \\
\text { жений НТП }\end{array}$ & $\begin{array}{l}\text { Эта особенность характеризуется тем, что при развитии } \\
\text { производства и внедрении достижений НТП, прежде всего, } \\
\text { необходимо вносить изменения в те производственные ресур- } \\
\text { сы, которые имеют наиболее долгий срок службы, а затем } \\
\text { проводить изменения в других ресурсах, входящих в состав } \\
\text { потенциала предприятия. В первую очередь необходимо } \\
\text { внедрять новые технологии производства, а потом изменять } \\
\text { структуру основных фондов, информационного обеспечения } \\
\text { производства и повышать квалификацию персонала }\end{array}$ & $\begin{array}{l}\text { Показывает } \\
\text { возможности } \\
\text { развития про- } \\
\text { изводственного } \\
\text { потенциала пред- } \\
\text { приятия }\end{array}$ \\
\hline Гибкость & $\begin{array}{l}\text { Предполагает возможность изменения номенклатуры и } \\
\text { ассортимента продукции без существенных изменений в ре- } \\
\text { сурсах производственного потенциала. Это особенно важно } \\
\text { для многономенклатурных производств, которые должны } \\
\text { иметь возможность при изменении спроса на выпускаемую } \\
\text { продукции осваивать производство других видов продукции }\end{array}$ & $\begin{array}{l}\text { Отражает возмож- } \\
\text { ности развития } \\
\text { и использования } \\
\text { производственного } \\
\text { потенциала }\end{array}$ \\
\hline Мощность & $\begin{array}{l}\text { Проявляется в том, что производственный потенциал } \\
\text { характеризует предприятия по выпуску продукции, т. е. } \\
\text { обладает мощностью. Эта особенность показывает возмож- } \\
\text { ность количественного определения и расчета величины } \\
\text { производственного потенциала предприятия }\end{array}$ & $\begin{array}{l}\text { Характеризует } \\
\text { возможность } \\
\text { расчета величины } \\
\text { производственного } \\
\text { потенциала пред- } \\
\text { приятия }\end{array}$ \\
\hline
\end{tabular}

Характерные особенности производственного потенциала можно подразделить на две группы: структурные и результирующие. Структурные особенности отражают состав и структуру производственного потенциала. К ним относятся: целостность, сложность, взаимозаменяемость или альтернативность элементов производственного потенциала, взаимосвязь и взаимодействие элементов производственного потенциала. Результирующие особенности характеризуют развитие и использование производственного потенциала предприятия. $K$ этой группе относятся следующие особенности: способность к восприятию достижений НТП, гибкость, мощность. Наибольшее значение имеют результирующие особенности производственного потенциала, так как они позволяют более целенаправленно внедрять достижения НТП в производство, учитывать возможности изменения конъюнктуры рынка и проводить оценку производственного потенциала и уровня его использования [10]. Классификация характерных особенностей и свойств производственного потенциала предприятия представлена на рисунке.

\section{Baikal Research Journal}




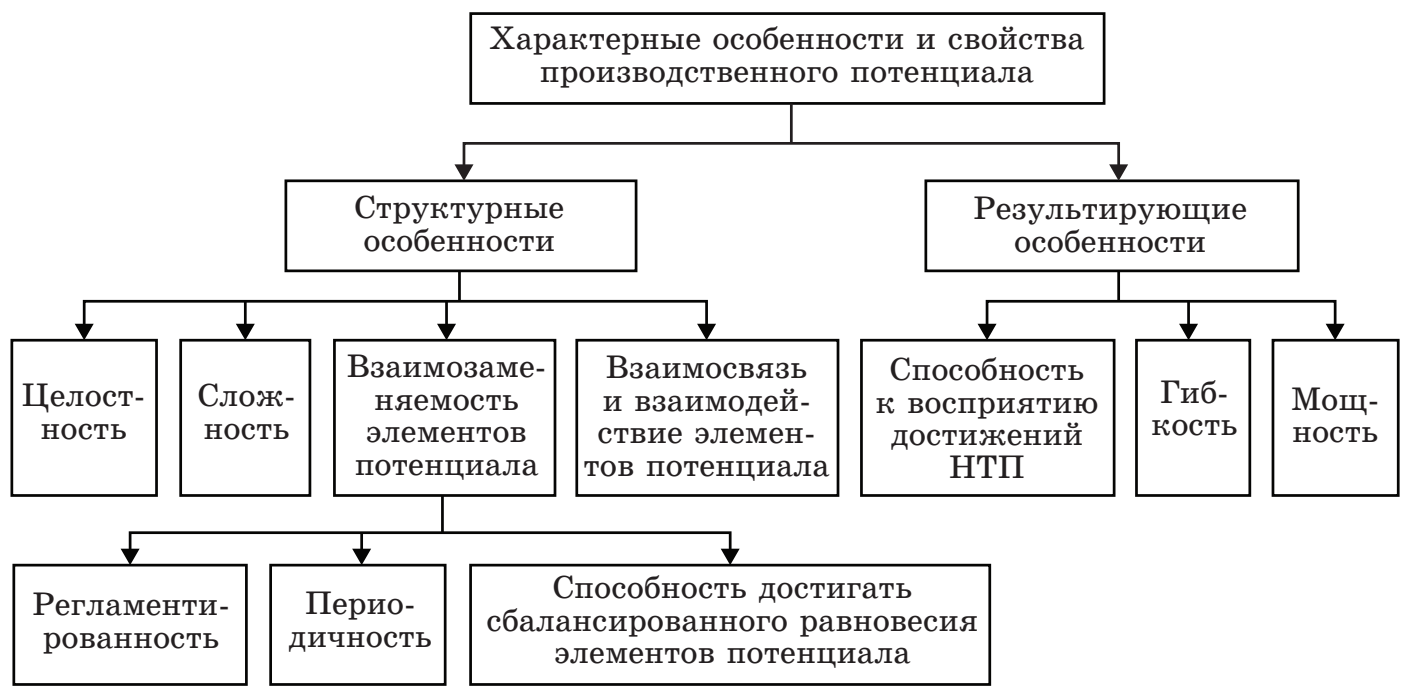

Классификация характерных особенностей

и свойств производственного потенциала предприятия

Методы расчета производственного потенциала подробно рассмотрены в работе [12]. В табл. 2 представлены основные сравнительные характеристики методов расчета производственного потенциала предприятия.

Таблица 2

Основные сравнительные характеристики методов расчета производственного потенциала предприятия

\begin{tabular}{|c|c|c|}
\hline Название метода & Сущность метода & Особенности и сферы применения \\
\hline $\begin{array}{l}\text { Эквивалентный } \\
\text { метод }\end{array}$ & $\begin{array}{l}\text { Оценка производ- } \\
\text { ственного потенциала } \\
\text { осуществляется в виде } \\
\text { величины какого-либо } \\
\text { из его элементов, в } \\
\text { который переводятся с } \\
\text { помощью специальных } \\
\text { коэффициентов другие } \\
\text { элементы потенциала. } \\
\text { Этот метод основан } \\
\text { на свойстве взаимо- } \\
\text { заменяемости элемен- } \\
\text { тов потенциала }\end{array}$ & $\begin{array}{l}\text { Этот метод позволяет выразить величину произ- } \\
\text { водственного потенциала в виде величины одного } \\
\text { из его элементов, но имеет следующие недостатки: } \\
\text { - в этом случае производственный потенциал } \\
\text { определяется в единицах измерения того ресурса, } \\
\text { в который переводятся другие виды ресурсов; } \\
\text { - существует определенная проблема в достовер- } \\
\text { ности определения коэффициентов замещения и } \\
\text { оценки состава и качества ресурсов; } \\
\text { - такие элементы, как технология и информация } \\
\text { при использовании этого метода, либо не учитыва- } \\
\text { ются вообще, либо учитываются незначительно }\end{array}$ \\
\hline
\end{tabular}

\section{Baikal Research Journal}


Окончание табл. 2

\begin{tabular}{|c|c|c|}
\hline Название метода & Сущность метода & Особенности и сферы применения \\
\hline $\begin{array}{l}\text { Корреля- } \\
\text { ционный метод }\end{array}$ & $\begin{array}{l}\text { Предполагает исполь- } \\
\text { зование различных } \\
\text { корреляционно-рег- } \\
\text { рессионных моделей } \\
\text { при определении } \\
\text { величины производст- } \\
\text { венного потенциала }\end{array}$ & $\begin{array}{l}\text { Этот метод в целом может использоваться для } \\
\text { определения потенциала национальной экономи- } \\
\text { ки и ее отраслей по производству определенных } \\
\text { видов продукции. Но его использование на уровне } \\
\text { предприятий затруднено тем, что он не учитывает } \\
\text { особенности деятельности предприятий разных } \\
\text { отраслей }\end{array}$ \\
\hline $\begin{array}{l}\text { Стоимостный } \\
\text { метод }\end{array}$ & $\begin{array}{l}\text { Предполагает опреде- } \\
\text { ление стоимости } \\
\text { каждого из элементов } \\
\text { потенциала, а затем } \\
\text { и общей стоимости } \\
\text { производственного } \\
\text { потенциала как суммы } \\
\text { стоимостей основных } \\
\text { производственных } \\
\text { фондов, персонала } \\
\text { (кадров), технологии и } \\
\text { информации }\end{array}$ & $\begin{array}{l}\text { Используется для: } \\
\text { - определения общей стоимости производственных } \\
\text { ресурсов, которыми располагает предприятие; } \\
\text { - оценки общей эффективности использования } \\
\text { производственных ресурсов предприятия; } \\
\text { - обобщающей оценки эффективности деятельно- } \\
\text { сти предприятия в целом; } \\
\text { - определения стоимости предприятия и решении } \\
\text { вопросов о необходимости продажи его объектов } \\
\text { или дополнительной эмиссии ценных бумаг }\end{array}$ \\
\hline $\begin{array}{l}\text { Смешанный } \\
\text { или комбини- } \\
\text { рованный метод }\end{array}$ & $\begin{array}{l}\text { Предполагает сочета- } \\
\text { ние различных мето- } \\
\text { дов при определении } \\
\text { величины производ- } \\
\text { ственного потенциала }\end{array}$ & Те же, что при использовании стоимостного метода \\
\hline
\end{tabular}

Наибольшее практическое значение имеет стоимостный метод, так как может быть использован для определения стоимости предприятия. При оценке предприятий используются различные методы, основанные на трех подходах: затратном, сравнительном и доходном.

На затратном подходе базируются методы: количественного анализа, разбивки по компонентам, сравнительной единицы, балансовой стоимости, замещения, ликвидационной стоимости. Он основан на мнении потенциального инвестора о том, что он не заплатит больше средств за тот или иной объект, чем их потребуется для того, чтобы построить аналогичный объект. При определении стоимости предприятия учитываются затраты на создание нового объекта. Использование данных о величине потенциала уточняет расчеты стоимости предприятия, так как учитывается информация о величине производственных ресурсов, необходимых для деятельности предприятия.

Сравнительный подход предполагает использование методов: парных продаж, количественного и качественного анализа продаж, отраслевых соотношений. Он может быть реализован при достаточно развитом рынке продаж родственных объектов или предприятий. Его применение заключается в проведении сравнительного анализа сделок купли-продажи или аренды на соответствующем рынке, сопоставлении оцениваемого объекта с родственными объектами, выбранными для сравнения, и внесением необходимых корректировок в стоимость оцениваемого объекта. Очевидно, что при проведении сравнительного анализа стоимости объектов, прежде всего, необходимо сравнивать их производственные возможности, т. е. величины производственных потенциалов. Это позволит учитывать при оценке предприятий не только различия в объемах производственной площади, транспортной доступности, месторасположении, но и качественное отличие более высокого порядка, заключающееся в стоимости производственных ресурсов.

Доходный подход к определению стоимости предприятий может быть реализован с использованием методов: валовой ренты, прямой капитализации, капита-

\section{Baikal Research Journal}

электронный научный журнал Байкальского государственного университета 
лизации доходов, дисконтирования денежных потоков. Он основан на определении и ожидании доходов от того или иного объекта в будущем. Естественно, что доходность предприятия во многом определяется величиной производственного потенциала и уровня его использования. В этом случае дополнительно могут использоваться при оценке текущие и прогнозируемые показатели потенциалоотдачи и эффективности использования производственного потенциала.

Таким образом, считаем, что учет информации о величине и уровне использования производственного потенциала предприятия позволит определять его стоимость более точно и обоснованно.

\section{Список использованной литературы}

1. Баранов И. В. Обоснование резервов производственных мощностей промышленных предприятий / И. В. Баранов, Л. И. Шинкарева // Известия Юго-Западного государственного университета. Сер.: Экономика. Социология. Менеджмент. - 2014. - № 4. - С. 77-81.

2. Каргинова М. А. Анализ факторов, определяющих производственную мощность предприятия / М. А. Каргинова // Наука и образование: хозяйство и экономика; предпринимательство; право и управление. - 2016. - № 5. - С. 18-21.

3. Маршова Т. Н. Производственные мощности российской промышленности через призму кризисных событий / Т. Н. Маршова // Российский экономический журнал. 2010. - № 4. - С. 11-31.

4. Петров П. А. Формирование единой методологии контроллинга стратегического потенциала промышленного предприятия / П. А. Петров // Вопросы управления. — 2011. № 3. - C. 128-137.

5. Тертышник М. И. Особенности планирования и определения производственных мощностей нефтехимических предприятий / М. И. Тертышник // Известия Иркутской государственной экономической академии. - 2016. - T. 26, № 3. - C. 411-418. - DOI: 10.17150/1993-3541.2016.26(3).411-418.

6. Ревуцкий Л. Д. Инвестиционный капитал и инвестиционный потенциал предприятия / Л. Д. Ревуцкий // Московский Оценщик. - 2010. - № 6. - С. 7-13.

7. Рогов В. Ю. Геоэкономические аспекты развития регионов / В. Ю. Рогов, М. Л. Багайников // Вестник Забайкальского государственного университета. — 2016. — № 8. C. $116-125$.

8. Рыков В. М. Теоретические аспекты сущности производственного потенциала организаций агропромышленного комплекса / В. М. Рыков // Известия Иркутской государственной экономической академии. - 2012. - № 2 (82). - С. 67-70.

9. Тертышник М. И. Потенциальные возможности предприятия: проблемы определения и оценки / М. И. Тертышник // Известия Иркутской государственной экономической академии. - 2015. - Т. 25, № 4. - С. 613-620. — DOI: 10.17150/1993-3541.2015.25(4).613-620.

10. Тертышник М. И. Экономика предприятия : учеб. пособие / М. И. Тертышник. М. : Инфра-М, 2016. -328 с.

11. Шуплецов А. Ф. Создание экспертной системы для оценки потенциала производственного предпринимательства в нефтепереработке и нефтехимии на основе теории нечетких множеств / А. Ф. Шуплецов, Д. В. Буньковский // Известия Иркутской государственной экономической академии. - 2011. - № 3 (77). - С. 82-85.

12. Тертышник М. И. Оценка производственного потенциала предприятия и научно-технического уровня производства / М. И. Тертышник // Известия Иркутской государственной экономической академии. - 2012. - № 1 (81). - С. 98-102.

\section{References}

1. Baranov I. V., Shinkareva L. I. Rationale reserves of production capacities of industrial enterprises. Izvestiya Yugo-Zapadnogo gosudarstvennogo universiteta. Seriya: Ekonomika. Sotsiologiya. Menedzhment = Bulletin of SouthWest State University. Series Economics. Sociology. Management, 2014, no. 4, pp. 77-81. (In Russian).

2. Karginova M. A. Analysis of factors determining company's industrial facility. Nauka $i$ obrazovanie: khozyaistvo i ekonomika; predprinimatel'stvo; pravo $i$ upravlenie $=$ Science and

\section{Baikal Research Journal}

электронный научный журнал Байкальского государственного университета 
Education: Industry and Economics; Entrepreneurship; Law and Management, 2016, no. 5, pp. 18-21. (In Russian).

3. Marshova T. N. Performance potential of the Russian industry through the prism of crisis events. Rossiiskii ekonomicheskii zhurnal = Russian Economic Journal, 2010, no. 4, pp. 11-31. (In Russian).

4. Petrov P. A. Formation of the methodology of controlling the strategic potential of industrial enterprises. Voprosy upravleniya = Issues of Management, 2011, no. 3, pp. 128-137. (In Russian).

5. Tertyshnik M. I. Planning and assessing production capacities of petrochemical enterprises. Izvestiya Irkutskoi gosudarstvennoi ekonomicheskoi akademii = Bulletin of Irkutsk State Economics Academy, 2016, vol. 26, no. 3, pp. 411-418. DOI: 10.17150/19933541.2016.26(3).411-418. (In Russian).

6. Revutsky L.D. Investment capital and company's investment potential. Moskovskii Otsenshchik = Moscow Appraiser, 2010, no. 6, pp. 7-13. (In Russian).

7. Rogov V. Y., Baranikov M. L. Geoeconomic aspects of regions development. Vestnik Zabaikal'skogo gosudarstvennogo universiteta = Zabaikalye State University Journal, 2016, no. 8, pp. 116-125. (In Russian).

8. Rykov V. M. Theoretical aspects of essence of production potential of agro-industrial enterprises. Izvestiya Irkutskoi gosudarstvennoi ekonomicheskoi akademii = Bulletin of Irkutsk State Economics Academy, 2012, no. 2 (82), pp. 67-70. (In Russian).

9. Tertyshnik M. I. Enterprise's potential: problems of defining and evaluating. Izvestiya Irkutskoi gosudarstvennoi ekonomicheskoi akademii = Bulletin of Irkutsk State Economics Academy, 2015, vol. 25, no. 4, pp. 613-620. DOI: 10.17150/1993-3541.2015.25(4).613-620. (In Russian).

10. Tertyshnik M. I. Ekonomika predpriyatiya [Business Economy]. Moscow, Infra-M Publ., 2016. 328 p.

11. Shupletzov A. F., Bynkovsky D. V. Creation of expert system for estimating industrial entrepreneurship potential in oil refining and petro chemistry on the basis of fuzzy-set theory. Izvestiya Irkutskoi gosudarstvennoi ekonomicheskoi akademii = Bulletin of Irkutsk State Economics Academy, 2011, no. 3 (77), pp. 82-85. (In Russian).

12. Tertyshnik M. I. Assessment of production potential and estimation of scientific and technical level of production. Izvestiya Irkutskoi gosudarstvennoi ekonomicheskoi akademii= Bulletin of Irkutsk State Economics Academy, 2012, no. 1 (81), pp. 98-102. (In Russian).

\section{Информация об авторе}

Тертышник Михаил Иванович - кандидат экономических наук, доцент, кафедра экономики предприятия и предпринимательской деятельности, Байкальский государственный университет, 664003, г. Иркутск, ул. Ленина, 11, e-mail: mtertyshnik@yandex.ru.

\section{Author}

Mikhail I. Tertyshnik - PhD in Economics, Associate Professor, Chair of Enterprise Economy and Entrepreneurship, Baikal State University, 11 Lenin St., 664003, Irkutsk, Russian Federation; e-mail: mtertyshnik@yandex.ru.

\section{Библиографическое описание статьи}

Тертышник М. И. Оценка уровня использования и проблемы определения потенциальных возможностей предприятий / М. И. Тертышник // Baikal Research Journal. 2017. - T. 8, № 2. - DOI: 10.17150/2411-6262.2017.8(2).29.

\section{Reference to article}

Tertyshnik M. I. Assessing level of use and problems of determining performance potential of businesses. Baikal Research Journal, 2017, vol. 8, no. 2. DOI: 10.17150/24116262.2017.8(2).29. (In Russian).

\section{Baikal Research Journal}

